\title{
Skew - Commuting Derivations of Noncommutative Prime Rings
}

\author{
Mehsin Jabel Atteya ${ }^{*}$, Dalal Ibraheem Rasen \\ Department of Mathematics, College of Education, Al-Mustansiriyah University, Baghdad, Iraq
}

Copyright (C) 2014Horizon Research Publishing All rights reserved.

\begin{abstract}
The main purpose of this paper is study and investigate a skew-commuting and skew-centralizing $\mathrm{d}$ and $\mathrm{g}$ be a derivations on noncommutative prime ring and semiprime ring $R$, we obtain the derivation $d(R)=0$ (resp. $\mathrm{g}(\mathrm{R})=0)$.
\end{abstract}

Keywords Skew-commuting, Derivation, Noncommutative Prime Ring, Semiprime Ring

2000Mathematics Subject Classification: 47A50, 47B50

\section{Introduction}

Derivations on rings help us to understand rings better and also derivations on rings can tell us about the structure of the rings. For instance a ring is commutative if and only if the only inner derivation on the ring is zero. Also derivations can be helpful for relating a ring with the set of matrices with entries in the ring (see, [5]). Derivations play a significant role in determining whether a ring is commutative, see ( [1],[3],[4],[18],[19] and [20]).Derivations can also be useful in other fields. For example, derivations play a role in the calculation of the eigenvalues of matrices (see, [2]) which is important in mathematics and other sciences, business and engineering. Derivations also are used in quantum physics(see, [18]). Derivations can be added and subtracted and we still get a derivation, but when we compose a derivation with itself we do not necessarily get a derivation. The history of commuting and centralizing mappings goes back to (1955) when Divinsky [6] proved that a simple Artinian ring is commutative if it has a commuting nontrivial automorphism. Two years later, Posner[7]has proved that the existence of a non- zero centralizing derivation on prime ring forces the ring to be commutative (Posner's second theorem).Luch [8]generalized the Divinsky result, we have just mentioned above, to arbitrary prime ring. In[9] M.N.Daif, proved that, let $\mathrm{R}$ be a semiprime ring and $\mathrm{d}$ a derivation of $\mathrm{R}$ with $\mathrm{d}^{3} \neq 0$.If $\left[\mathrm{d}_{(} \mathrm{x}_{)}, \mathrm{d}_{(\mathrm{y})}\right]=0$ for all $\mathrm{x}, \mathrm{y} \in \mathrm{R}$, then $\mathrm{R}$ contains a non-zero central ideal. M.N.Daif and H.E. Bell [10] proved that, let $\mathrm{R}$ be a semiprime ring admitting a derivation $\mathrm{d}$ for which either $\mathrm{xy}+\mathrm{d}(\mathrm{xy})=\mathrm{yx}+\mathrm{d}(\mathrm{yx})$ for all $\mathrm{x}, \mathrm{y}$ $\in \mathrm{R}$ or $\mathrm{xy}-\mathrm{d}(\mathrm{xy})=\mathrm{yx}-\mathrm{d}(\mathrm{yx})$ for all $\mathrm{x}, \mathrm{y} \in \mathrm{R}$, then $\mathrm{R}$ is commutative. V.DeFilippis [11] proved that, when $\mathrm{R}$ be a prime ring let $\mathrm{d}$ a non-zero derivation of $\mathrm{R}, \mathrm{U} \neq(0)$ a two-sided ideal of $\mathrm{R}$, such that $\mathrm{d}([\mathrm{x}, \mathrm{y}])=[\mathrm{x}, \mathrm{y}]$ for all $\mathrm{x}, \mathrm{y} \in \mathrm{U}$, then $\mathrm{R}$ is commutative. Recently A.H. Majeed and Mehsin Jabel [12], give some results as, let $\mathrm{R}$ be a 2-torsion free semiprime ring and $\mathrm{U}$ a non-zero ideal of $\mathrm{R}$. $\mathrm{R}$ admitting a non-zero derivation $\mathrm{d}$ satisfying $\mathrm{d}([\mathrm{d}(\mathrm{x}), \mathrm{d}(\mathrm{y})])=[\mathrm{x}, \mathrm{y}]$ for all $\mathrm{x}, \mathrm{y} \in \mathrm{U}$. If $\mathrm{d}$ acts as a homomorphism, then $\mathrm{R}$ contains a non-zero central ideal. Our aim in this paper is to investigate skew-commuting $\mathrm{d}$ and $\mathrm{g}$ be derivations on noncommutative prime ring and semiprime ring $\mathrm{R}$.

\section{Preliminaries}

Throughout $\mathrm{R}$ will represent an associative ring with identity, $\mathrm{Z}(\mathrm{R})$ denoted to the center of $\mathrm{R}, \mathrm{R}$ is said to be $\mathrm{n}$-torsion free, where $\mathrm{n} \neq 0$ is an integer, if whenever $\mathrm{n} x=$ 0 ,with $x \in R$, then $x=0$. We recall that $R$ is semiprime if $x R x=(0)$ implies $x=0$ and it is prime if $x R y=(0)$ implies $x$ $=0$ or $\mathrm{y}=0$.A prime ring is semiprime but the converse is not true in general. An additive mapping $\mathrm{d}: \mathrm{R} \rightarrow \mathrm{R}$ is called a derivation if $d(x y)=d(x) y+x d(y)$ holds for all $x, y \in R$, and is said to be n-centralizing on $U$ (resp. n-commuting on $U$ ), if $\left[\mathrm{x}^{\mathrm{n}}, \mathrm{d}(\mathrm{x})\right] \in \mathrm{Z}(\mathrm{R})$ holds for all $\mathrm{x} \in \mathrm{U}$ (resp. $\left[\mathrm{x}^{\mathrm{n}}, \mathrm{d}(\mathrm{x})\right]=0$ holds for all $x \in U$, where $n$ be a positive integer. Also is called skew-centralizing on subset $U$ of $R$ (resp. skew-commuting on subset $U$ of $R$ )if $d(x) x+x d(x) \in Z(R)$ holds for all $x \in U(\operatorname{resp} . d(x) x+x d(x)=0$ holds for all $x \in$ $\mathrm{U})$, and $\mathrm{d}$ acts as a homomorphism on $\mathrm{U}($ resp. anti-homomorphism on $U$ ) if $d(x y)=d(x) d(y)$ holds for all $x, y$ $\in U($ resp. if $d(x y)=d(y) d(x)$ holds for all $x, y \in U)$. We write $[\mathrm{x}, \mathrm{y}]$ for $\mathrm{xy}-\mathrm{yx}$ and make extensive use of basic commutator identities $[\mathrm{xy}, \mathrm{z}]=\mathrm{x}[\mathrm{y}, \mathrm{z}]+[\mathrm{x}, \mathrm{z}] \mathrm{y}$ and $[\mathrm{x}, \mathrm{yz}]=\mathrm{y}$ $[\mathrm{x}, \mathrm{z}]+[\mathrm{x}, \mathrm{y}] \mathrm{z}$. In some parts of the proof our theorems(3.1 and 3.2 ), we using same technique in [21].

First we list the lemmas which will be needed in the sequel.

\section{Lemma1[7]}


If $\mathrm{d}$ is commuting derivation on noncommutative prime ring, then $\mathrm{d}=0$.

\section{Lemma 2 [13:Theorem1.2]}

Let $\mathrm{S}$ be a set and $\mathrm{R}$ a semiprime ring. If functions $\mathrm{d}$ and $\mathrm{g}$ of $S$ into $R$ satisfy $d(s) x g(t)=g(s) x d(t)$ for all $s, t \in S, x \in R$, then there exists idempotents $\alpha_{1}, \alpha_{2}, \alpha_{3}, \in \mathrm{C}$ and an invertible element $\lambda \in \mathrm{C}$ such that $\alpha_{\mathrm{i}} \alpha_{\mathrm{j}}=0$, for $\mathrm{i} \neq \mathrm{j}$,

$\alpha_{1}+\alpha_{2}+\alpha_{3}=1$, and $\alpha_{1} \mathrm{~d}(\mathrm{~s})=\lambda \alpha_{1} \mathrm{~g}(\mathrm{~s}), \alpha_{2} \mathrm{~g}(\mathrm{~s})=0, \alpha_{3} \mathrm{~d}(\mathrm{~s})=0$ hold for all $\mathrm{s} \in \mathrm{S}$.

\section{Lemma 3[14: Theorem 2]}

Let $\mathrm{R}$ be a 2-torsion free semiprimering. If an additive mapping $\mathrm{g}: \mathrm{d} \rightarrow \mathrm{d}$ is skew-commuting on $\mathrm{R}$, then $\mathrm{d}=0$.

\section{Lemma 4 [15: Lemma 4]}

Let $\mathrm{R}$ be a semiprimering and $\mathrm{U}$ a non-zero ideal of $\mathrm{R}$.If $\mathrm{d}$ is a derivation of $R$ which is centralizing on $U$, then $d$ is commuting on $\mathrm{U}$.

\section{The Main Results}

\section{Theorem 3.1}

Let $\mathrm{R}$ be a noncommutative prime ring, $\mathrm{d}$ and $\mathrm{g}$ be a derivations of $R$. If $R$ admits to satisfy $d(x) x+x g(x) \in Z(R)$ for all $x \in R$, then $d(R)=0$ (resp. $g(R)=0$ ) or wd (resp. wg) is central for all $w \in Z(R)$.

Proof: At first we suppose there exists an element say $w \in$ $\mathrm{R}$, such that

$\mathrm{w} \in \mathrm{Z}(\mathrm{R})$. Let $\mathrm{w}$ be a non-zero element of $\mathrm{Z}(\mathrm{R})$.By linearizing our relation

$\mathrm{d}(\mathrm{x}) \mathrm{x}+\mathrm{xg}(\mathrm{x}) \in \mathrm{Z}(\mathrm{R})$, we obtain

$\mathrm{d}(\mathrm{x}) \mathrm{y}+\mathrm{d}(\mathrm{y}) \mathrm{x}+\mathrm{xg}(\mathrm{y})+\mathrm{yg}(\mathrm{x}) \in \mathrm{Z}(\mathrm{R})$ for all $\mathrm{x}, \mathrm{y} \in \mathrm{R}$.

Taking $\mathrm{y}=\mathrm{w}$ in $(1)$, we get

$\mathrm{d}(\mathrm{x}) \mathrm{w}+\mathrm{d}(\mathrm{w}) \mathrm{x}+\mathrm{xg}(\mathrm{w})+\mathrm{wg}(\mathrm{x}) \in \mathrm{Z}(\mathrm{R})$ for all $\mathrm{x} \in \mathrm{R}$.

Again in (1) replacing y by $\mathrm{w}^{2}$, we obtain

$\mathrm{d}(\mathrm{x}) \mathrm{w}^{2}+\mathrm{d}\left(\mathrm{w}^{2}\right) \mathrm{x}+\mathrm{xg}\left(\mathrm{w}^{2}\right)+\mathrm{w}^{2} \mathrm{~g}(\mathrm{x}) \in \mathrm{Z}(\mathrm{R})$ for all $\mathrm{x} \in \mathrm{R}$, since $d$ and $g$ be a derivations of $R$ and $w \in Z(R)$, we obtain

$\mathrm{d}(\mathrm{x}) \mathrm{w} 2+2 \mathrm{wd}(\mathrm{w}) \mathrm{x}+\mathrm{x}(2 \mathrm{wg}(\mathrm{w}))+\mathrm{w} 2 \mathrm{~g}(\mathrm{x}) \in \mathrm{Z}(\mathrm{R})$.

for all $x \in R$, then

$\mathrm{w}(\mathrm{d}(\mathrm{w}) \mathrm{x}+\mathrm{xg}(\mathrm{w}))+\mathrm{w}(\mathrm{d}(\mathrm{x}) \mathrm{w}+\mathrm{d}(\mathrm{w}) \mathrm{x}+\mathrm{xg}(\mathrm{w})+\mathrm{wg}(\mathrm{x})) \in \mathrm{Z}(\mathrm{R})$

for all $x \in R$. (4)

According to (2) the relation (4) gives

$\mathrm{w}(\mathrm{d}(\mathrm{w}) \mathrm{x}+\mathrm{xg}(\mathrm{w})) \in \mathrm{Z}(\mathrm{R})$ for all $\mathrm{x} \in \mathrm{R}$. Thus

$[w(d(w) x+x g(w)), y]=0$ for all $x, y \in R$. Then

$\mathrm{w}[\mathrm{d}(\mathrm{w}) \mathrm{x}+\mathrm{xg}(\mathrm{w}), \mathrm{y}]+[\mathrm{w}, \mathrm{y}](\mathrm{d}(\mathrm{w}) \mathrm{x}+\mathrm{xg}(\mathrm{w}))=0$

for all $\mathrm{x}, \mathrm{y} \in \mathrm{R}$.

Since $w \in Z(R)$, then (5) gives

$\mathrm{w}[\mathrm{d}(\mathrm{w}) \mathrm{x}+\mathrm{xg}(\mathrm{w}), \mathrm{y}]=0$ for all $\mathrm{x}, \mathrm{y} \in \mathrm{R}$. $[d(x) w+d(w) x+x g(w)+w g(x), y]=0$ for all $x, y \in R$. Then

$$
[d(x) w+w g(x), y]=-[d(w) x+g(w), y] \text { for all } x, y \in R \text {. }
$$

Now from (6) and (7), we obtain

$w[d(x) w+w g(x), y]=0$ for all $x, y \in R$. Since $w \in Z(R)$, this relation gives

$w 2[d(x)+g(x), y]=0$ for all $x, y \in R$.

Replacing y by zy, with using (8), we get

$\mathrm{w}^{2} \mathrm{z}[\mathrm{d}(\mathrm{x})+\mathrm{g}(\mathrm{x}), \mathrm{y}]=0$ for all $\mathrm{x}, \mathrm{y} \in \mathrm{R}$, which implies

$\mathrm{wZw}[\mathrm{d}(\mathrm{x})+\mathrm{g}(\mathrm{x}), \mathrm{y}]=0$ forall $\mathrm{x}, \mathrm{y} \in \mathrm{R}$.

Replacing $\mathrm{z}$ by $[\mathrm{d}(\mathrm{x})+\mathrm{g}(\mathrm{x}), \mathrm{y}] \mathrm{z}$ and since $\mathrm{R}$ is prime ring , which implies

$\mathrm{w}[\mathrm{d}(\mathrm{x})+\mathrm{g}(\mathrm{x}), \mathrm{y}]=0$ for all $\mathrm{x}, \mathrm{y} \in \mathrm{R}$. Then

$[\mathrm{w}(\mathrm{d}(\mathrm{x})+\mathrm{g}(\mathrm{x})), \mathrm{y}]=0$ for all $\mathrm{x}, \mathrm{y} \in \mathrm{R}$. Thus

$\mathrm{w}(\mathrm{d}(\mathrm{x})+\mathrm{g}(\mathrm{x})) \in \mathrm{Z}(\mathrm{R})$ for all $\mathrm{x} \in \mathrm{Z}(\mathrm{R})$ for all $\mathrm{x} \in \mathrm{R}$.

Since $w \in Z(R)$ and $d, g$ are derivations, therefore, wd, wg and $\mathrm{w}(\mathrm{d}+\mathrm{g})$ are derivations of $\mathrm{R}$.

Further, from (10) we obtain $\mathrm{w}(\mathrm{d}+\mathrm{g})$ is central and Lemma4,we obtain a commuting derivation. Then by [16:Proposition 2.3], we get

$(\mathrm{w}(\mathrm{d}+\mathrm{g}))(\mathrm{u})[\mathrm{x}, \mathrm{y}]=0$ for all $\mathrm{u}, \mathrm{x}, \mathrm{y} \in \mathrm{R}$.

From (11) and the fact that $w d(u)+w g(u) \in Z(R)$, we obtain

$[(w d(u)+w g(u)) u, y]=(w d(u)+w g(u))[u, y]+[w d(u)+w g(u)$, $\mathrm{y}] \mathrm{u}=0$

for all $\mathrm{u}, \mathrm{y} \in \mathrm{R}$. Then

$[w d(u) u+w g(u) u, y]=0$ for all $u, y \in R$.

Since $w \in Z(R)$ and $d(u) u+u g(u) \in Z(R)$, therefore, $\mathrm{wd}(\mathrm{u}) \mathrm{u}+\operatorname{wug}(\mathrm{u}) \in \mathrm{Z}(\mathrm{R})$, thus (12) implies that

$[w d(u) u+w u g(u), y]=0$ for all $u, y \in R$.

Subtracting (13) and (12), we obtain $[w g(u) u-w u g(u), y]=0$ for all $u, y \in R$. Then $[w(g(u) u-u g(u)), y]=0$ for all $u, y \in R$. $[\mathrm{w}[\mathrm{g}(\mathrm{u}), \mathrm{u}], \mathrm{y}]=0$ for all $\mathrm{u}, \mathrm{y} \in \mathrm{R}$.

$[[\mathrm{wg}(\mathrm{u}), \mathrm{u}], \mathrm{y}]=0$ for all $\mathrm{u}, \mathrm{y} \in \mathrm{R}$. Thus, we obtain $[\mathrm{wg}(\mathrm{u}), \mathrm{u}] \in \mathrm{Z}(\mathrm{R})$ for all $\mathrm{u} \in \mathrm{R}$. Therefore, we obtain $\mathrm{wg}$ is a centralizing derivation. By Lemma 4, we get $\mathrm{wg}$ is a commuting derivation. Also by [16:Proposition2.3], we get that $w g(u) \in Z(R)$ for all $u \in R$. Since $w d(u)+w g(u) \in Z(R)$ and $w g(u) \in Z(R)$ for all $u \in R$, therefore, we obtain $w d(u)$ $\in Z(R)$ for all $u \in R$, thus $[w d(u), u]=0$ for all $u \in R$.

Then $w[d(u), u]+[w, u] d(u)=0$ for all $u \in R$. Since we suppose that $w \in Z(R)$, above relation reduces to $\mathrm{w}[\mathrm{d}(\mathrm{u}), \mathrm{u}]=0$ for all $\mathrm{u} \in \mathrm{R}$.

Left-multiplying by $r$, we get $\operatorname{wr}[\mathrm{d}(\mathrm{u}), \mathrm{u}]=0$ for all $\mathrm{u}, \mathrm{r} \in \mathrm{R}$. Then $\mathrm{wR}[\mathrm{d}(\mathrm{u}), \mathrm{u}]=(0)$. Since $\mathrm{R}$ is prime ring and $\mathrm{w} \neq 0$, we arrive to

$[\mathrm{d}(\mathrm{u}), \mathrm{u}]=0$ for all $\mathrm{u} \in \mathrm{R}$. By apply Lemma 1 , we obtain $d(R)=0(\operatorname{resp} \cdot g(R)=0)$.

If $\mathrm{w}=0$, then obviously, we obtain $\mathrm{d}(\mathrm{R})$ (resp.g(R)) is

Also from (2), we obtain 
central for all $w \in Z(R)$.

\section{Theorem 3.2}

Let $\mathrm{R}$ be a noncommutative prime ring, $\mathrm{d}$ be a skew-centralizing derivation of $\mathrm{R}$ (resp. $\mathrm{g}$ be a skewcentralizing derivation of $R$ ), if $R$ admits to satisfy $d(x) x+x g(x) \in Z(R)$ for all $x \in R$. Then $d(R)=0$ (resp. $\mathrm{g}(\mathrm{R})=0)$.

Proof: Let $\mathrm{x}_{0} \in \mathrm{R}$ and $\mathrm{c}=\mathrm{d}\left(\mathrm{x}_{0}\right) \mathrm{x}_{0}+\mathrm{x}_{0} \mathrm{~g}\left(\mathrm{x}_{\mathrm{o}}\right)$. Thus , according to our hypothesis, we obtain $c \in Z(R)$.Then by Theorem 3.1, we get cd and cg are commuting, then $[\operatorname{cd}(\mathrm{x}), \mathrm{y}]=0$ for all $\mathrm{x}, \mathrm{y}$ $\in \mathrm{R}$. Then

$\operatorname{cd}(\mathrm{x}) \mathrm{y}=\mathrm{ycd}(\mathrm{x})$ for all $\mathrm{x}, \mathrm{y} \in \mathrm{R}$.

Since $c \in Z(R)$, then above relation become

$d(x) y c=c y d(x)$ for all $x, y \in R$.

Now taking $\mathrm{S}=\mathrm{R}, \mathrm{g}(\mathrm{x})=\mathrm{c}$ with applying Lemma2 to (14), we obtain that there exist idempotents $\alpha_{1}, \alpha_{2}, \alpha_{3} \in \mathrm{C}$ and an invertible element $\lambda \in \mathrm{C}$ such that

$\alpha_{\mathrm{i}} \alpha_{\mathrm{j}}=0$ for $\mathrm{i} \neq \mathrm{j} \alpha_{1}+\alpha_{2}+\alpha_{3}=1$, and $\alpha_{1} \mathrm{~d}(\mathrm{x})=\lambda \alpha_{1} \mathrm{c}, \alpha_{2} \mathrm{c}=0, \alpha$ ${ }_{3} \mathrm{~d}(\mathrm{x})=0$ for all $\mathrm{x} \in \mathrm{R}$.

For the first identity of (15) replacing $x$ by $x y$ and using it again, we obtain

$\lambda \alpha_{1} c=\alpha_{1} d(x y)=\alpha_{1} d(x) y+x \alpha_{1} d(y)=\lambda \alpha_{1} c y+x \lambda \alpha_{1} c$ for all $x, y$ $\in$ R. Then

$\lambda \alpha{ }_{1} \mathrm{c}=\lambda \alpha_{1} \mathrm{cy}+\mathrm{x} \lambda \alpha_{1} \mathrm{c}$ for all $\mathrm{x}, \mathrm{y} \in \mathrm{R}$.

Replacing $\mathrm{y}$ by $-\mathrm{x}$ in (16), we obtain

$\lambda \alpha_{1} \mathrm{c}=\lambda \alpha_{1} \mathrm{c}(-\mathrm{x})+\mathrm{x} \alpha_{1} \mathrm{c}=-\mathrm{x} \lambda \alpha_{1} \mathrm{c}+\mathrm{x} \lambda \alpha_{1} \mathrm{c}=0$ for all $\mathrm{x} \in \mathrm{R}$. Thus, we get

$\lambda \alpha_{1} \mathrm{c}=0$. Therefore, the first identity of (15) become

$\lambda \alpha_{1} \mathrm{c}=\alpha_{1} \mathrm{~d}(\mathrm{x})$ for all $\mathrm{x} \in \mathrm{R}$. Hence, using (15), we obtain $\mathrm{d}(\mathrm{x})=\left(\alpha_{1}+\alpha_{2}+\alpha_{3}\right) \mathrm{d}(\mathrm{x})=\alpha_{2} \mathrm{~d}(\mathrm{x})$ for all $\mathrm{x} \in \mathrm{R}$. Then

$\operatorname{cd}(\mathrm{x})=\mathrm{c} \alpha_{2} \mathrm{~d}(\mathrm{x})=\alpha_{2} \operatorname{cd}(\mathrm{x})$ for all $\mathrm{x} \in \mathrm{R}$. Then, from second identity in (15), we obtain $c d(x)=0$ for all $x \in R$. Since $c g$ is commuting, then cg is central, therefore, analogously, it follows that $\operatorname{cg}(\mathrm{x})=0$ for all $\mathrm{x} \in \mathrm{R}$. Hence

$\operatorname{cd}(x) x=0$ and $x \operatorname{cg}(x)=\operatorname{cxg}(x)=0$ for all $x \in R$. Thus from these relations, we obtain $\mathrm{c}\left(\mathrm{d}\left(\mathrm{x}_{0} \mathrm{x}+\mathrm{xg}(\mathrm{x})\right)=0\right.$ for all $\mathrm{x} \in \mathrm{R}$.

In particular, $c\left(d\left(x_{0}\right) x_{0}+x_{0} g\left(x_{0}\right)\right)=c^{2}=0$. Since a semiprime ring has no nonzero central nilpotent, therefore, we get $\mathrm{c}=\mathrm{o}$, which implies $d\left(x_{0}\right) x_{0}+x_{0} g\left(x_{0}\right)=0$. Since $x_{0}$ is an arbitrary element of $\mathrm{R}$, therefore

$d(x) x+x g(x)=0$ for all $x \in R$.

If we taking $d(x)=g(x)$, then

$d(x) x+x d(x)=0$ for all $x \in R$. Then by using Lemma 3, we obtain $d(R)=0$ (resp. $g(R)=0)$.

If $d(x) \neq g(x)$, this case lead to $d(x) x+x g(x) \in Z(R)$ for all $x$ $\in \mathrm{R}$. By Theorem3.1, we complete our proof.

\section{Theorem 3.3}

Let $\mathrm{R}$ be a 2-torsion free semiprime ring with cancellation property. If $\mathrm{R}$ admits a derivation $\mathrm{d}$ to satisfy

(i) d acts as a skew-commuting on R.

(ii) $d$ acts as a skew-centralizing on $R$. Then $d(R)$ is commuting of R.
Proof: (i) Since d is skew-commuting, then

$\mathrm{d}(\mathrm{x}) \mathrm{x}+\mathrm{xd}(\mathrm{x})=\mathrm{o}$ for all $\mathrm{x} \in \mathrm{R}$.

Left -multiplying (18) by $\mathrm{x}$,we obtain

$x d(x) x+x 2 d(x)=0$ for all $x \in R$.

From (18), we get $d(x 2)=o$ for all $x \in R$.

In (20) replacing $x$ by $x+y$,we obtain $\mathrm{d}\left(\mathrm{x}^{2}\right)+\mathrm{d}(\mathrm{xy})+\mathrm{d}(\mathrm{yx})+\mathrm{d}\left(\mathrm{y}^{2}\right)=$ o for all $\mathrm{x}, \mathrm{y} \in \mathrm{R}$.

A according to (20), a above equation become $\mathrm{d}(\mathrm{xy})+\mathrm{d}(\mathrm{yx})=\mathrm{o}$ for all $\mathrm{x}, \mathrm{y} \in \mathrm{R}$. Then $d(x) y+x d(y)+d(y) x+y d(x)=0$ for all $x, y \in R$.

Replacing $\mathrm{y}$ by $\mathrm{x}^{2}$ and according to(20), we arrived to

$d(x) x 2+x 2 d(x)=0$ for all $x \in R$.

Then

$\mathrm{x} 2 \mathrm{~d}(\mathrm{x})=-\mathrm{d}(\mathrm{x}) \mathrm{x} 2$ for all $\mathrm{x} \in \mathrm{R}$.

By substituting (21) in (19), we get

$\mathrm{xd}(\mathrm{x}) \mathrm{x}-\mathrm{d}(\mathrm{x}) \mathrm{x}^{2}=\mathrm{o}$ for all $\mathrm{x} \in \mathrm{R}$. Then

$[\mathrm{x}, \mathrm{d}(\mathrm{x})] \mathrm{x}=\mathrm{O}$ for all $\mathrm{x} \in \mathrm{R}$. Then apply the cancellation property on $\mathrm{x}$,

we get, we obtain

$[\mathrm{x}, \mathrm{d}(\mathrm{x})]=\mathrm{o}$ for all $\mathrm{x} \in \mathrm{R}$. Then $\mathrm{d}(\mathrm{R})$ is commuting of $\mathrm{R}$.

(ii) We will discuss, when $\mathrm{d}$ acts as a skew- centralizing on $\mathrm{R}$.

Then we have $d(x) x+x d(x) \in Z(R)$ for all $x \in R$. $\mathrm{d}\left(\mathrm{x}^{2}\right) \in \mathrm{Z}(\mathrm{R})$ for all $\mathrm{x} \in \mathrm{R}$. i.e.

$$
[\mathrm{d}(\mathrm{x} 2), \mathrm{r}]=\mathrm{o} \text { for all } \mathrm{x}, \mathrm{r} \in \mathrm{R} \text {. }
$$

Also, by replacing $r$ by $x$ in(22), we obtain $(d(x)) x+x d(x)) x=x(d(x) x+x d(x))$ for all $x \in R$ Then $d(x) x^{2}+x d(x) x=x d(x) x+x^{2} d(x)$ for all $x \in R$. Then

$d(x) x^{2}-x^{2} d(x)=0$ for all $x \in R$. Then

$[\mathrm{d}(\mathrm{x}), \mathrm{x} 2]=\mathrm{o}$ for all $\mathrm{x} \in \mathrm{R}$.

$\operatorname{In}(22)$,replacing $x$ by $x+y$, we obtain

$\left[\mathrm{d}\left(\mathrm{x}^{2}\right)+\mathrm{d}(\mathrm{xy})+\mathrm{d}(\mathrm{ys})+\mathrm{d}\left(\mathrm{y}^{2}\right), \mathrm{r}\right]=\mathrm{o}$ for all $\mathrm{x}, \mathrm{y}, \mathrm{r} \in \mathrm{R}$.

According to(22), we obtain

$[d(x) y+x d(y)+d(y) x+y d(x), r]=o$ for all $x, y, r \in R$.

Replacing y by $x^{2}$, we obtain

$\left[\mathrm{d}(\mathrm{x}) \mathrm{x}^{2}+\mathrm{xd}\left(\mathrm{x}^{2}\right)+\mathrm{d}\left(\mathrm{x}^{2}\right) \mathrm{x}+\mathrm{x}^{2} \mathrm{~d}(\mathrm{x}), \mathrm{r}\right]=\mathrm{o}$ for all $\mathrm{x}, \mathrm{r} \in \mathrm{R}$.

According to (22) and (23), we get

$\left[x^{2} d(x)+x d\left(x^{2}\right)+x d\left(x^{2}\right)+x^{2} d(x), r\right]=o$ for all $x, r \in R$. Then

$2\left[\mathrm{x}^{2} \mathrm{~d}(\mathrm{x})+\mathrm{xd}\left(\mathrm{x}^{2}\right), \mathrm{r}\right]=\mathrm{o}$ for all $\mathrm{x}, \mathrm{r} \in \mathrm{R}$.

Since $\mathrm{R}$ is 2-torsion free, we obtain

$\left[x^{2} d(x)+x d\left(x^{2}\right), r\right]=0$ for all $x, r \in R$. Then

$\left[x\left(x d(x)+d\left(x^{2}\right)\right), r\right]=o$ for all $x, r \in R$. Then

$\mathrm{x}\left[\mathrm{xd}(\mathrm{x})+\mathrm{d}\left(\mathrm{x}^{2}\right), \mathrm{r}\right]+[\mathrm{x}, \mathrm{r}]\left(\mathrm{xd}(\mathrm{x})+\mathrm{d}\left(\mathrm{x}^{2}\right)\right)=\mathrm{o}$ for all $\mathrm{x}, \mathrm{r} \in \mathrm{R}$.

According to (22), above equation become

$x[x d(x), r]+[x, r]\left(x d(x)+d\left(x^{2}\right)\right)=o$ for all $x, r \in R$. Replacing $r$ by $x$, we obtain $x[x d(x), x]=0$ for all $x \in R$.

Then $\mathrm{x}^{2}[\mathrm{~d}(\mathrm{x}), \mathrm{x}]=\mathrm{o}$ for all $\mathrm{x} \in \mathrm{R}$. Apply the cancellation property on $\mathrm{x}^{2}$, we get $[\mathrm{d}(\mathrm{x}), \mathrm{x}]=\mathrm{o}$ for all $\mathrm{x} \in \mathrm{R}$. We complete the proof of theorem. 


\section{Theorem 3.4}

Let $\mathrm{R}$ be a 2-torsion free noncommutative prime ring. If $\mathrm{R}$ admits a derivation $d$ to satisfy one of following

(i) $\mathrm{d}$ acts as a homomorphism on $\mathrm{R}$. Then $\mathrm{d}(\mathrm{R})=0$.

(ii) $\mathrm{d}$ acts as an anti-homomorphism on $\mathrm{R}$. Then $\mathrm{d}(\mathrm{R})=0$.

Proof: (i) $\mathrm{d}$ acts as a homomorphism on $\mathrm{R}$. We have $\mathrm{d}$ is a derivation, then

$d(x y)=d(x) y+x d(y)$ for all $x, y \in R$. Then

$[d(x y), r]=[d(x) y, r]+[x d(y), r]$ for all $x, y, r \in R$. Since $d$ acts as a homomorphism, then $[\mathrm{d}(\mathrm{x}) \mathrm{d}(\mathrm{y}), \mathrm{r}]=[\mathrm{d}(\mathrm{x}) \mathrm{y}, \mathrm{r}]+[\mathrm{xd}(\mathrm{y}), \mathrm{r}]$ for all $\mathrm{x}, \mathrm{y}, \mathrm{r} \in \mathrm{R}$. Replacing $\mathrm{r}$ by $\mathrm{d}(\mathrm{y})$, we obtain

$[d(x), d(y)] d(y)=[d(x) y, d(y)]+[x d(y), d(y)]$ for all $x, y \in$ $\mathrm{R}$. Then

$[d(x), d(y)] d(y)=d(x)[y, d(y)]+[d(x), d(y)] y+[x, d(y)] d(y)$ for all $x, y \in R$.

Replacing y by $x$, we obtain $d(x)[x, d(x)]+[x, d(x)] d(x)=0$ for all $\mathrm{x} \in \mathrm{R}$.

Then $\left[\mathrm{d}(\mathrm{x})^{2}, \mathrm{x}\right]=\mathrm{o}$ for all $\mathrm{x} \in \mathrm{R}$. Then $\mathrm{d}(\mathrm{x})^{2} \in \mathrm{Z}(\mathrm{R})$ for all $\mathrm{x}$ $\in R$. Since $d$ acts as a homomorphism, then $d\left(x^{2}\right) \in Z(R)$ for all $x \in R$, i.e. $d(x) x+x d(x) \in Z(R)$ for all $x \in R$, then $d$ is skew-centralizing on R. Then by Theorem3.2, we obtain $\mathrm{d}(\mathrm{R})=0$.

The proof of (ii) is similar. We complete the proof of theorem.

\section{Remark 3.5}

In Theorem 3.3 and Theorem 3.4, we can't exclude the condition char. $R \neq 2$, as it is shown in the following example.

\section{Example 3.6}

Let $\mathrm{R}$ be the ring of all $2 \times 2$ matrices over a field $\mathrm{F}$ with char. $\mathrm{R}=2$, let $\mathrm{a}=\left(\begin{array}{ll}0 & 0 \\ 0 & 1\end{array}\right), \mathrm{R}=\left\{\left(\begin{array}{ll}a & b \\ b & a\end{array}\right) / \mathrm{a}, \mathrm{b} \in \mathrm{F}\right\}$. Let $\mathrm{d}$ be the inner derivation given by:

$$
\mathrm{d}(\mathrm{x})=\mathrm{x}\left(\begin{array}{ll}
0 & 0 \\
0 & 1
\end{array}\right)-\left(\begin{array}{ll}
0 & 0 \\
0 & 1
\end{array}\right) \mathrm{x}, \text { when } \mathrm{x} \in \mathrm{R} \text {, then } \mathrm{x}=\left(\begin{array}{ll}
a & b \\
b & a
\end{array}\right) \text {, }
$$$$
\text { therefore, } \mathrm{d}(\mathrm{x})=\left(\begin{array}{cc}
0 & b \\
-b & 0
\end{array}\right) \text {. Then }
$$$$
\mathrm{d}(\mathrm{x}) \mathrm{x}+\mathrm{xd}(\mathrm{x})=\left(\begin{array}{cc}
0 & b \\
-b & 0
\end{array}\right)\left(\begin{array}{ll}
a & b \\
b & a
\end{array}\right)+\left(\begin{array}{cc}
a & b \\
b & a
\end{array}\right)\left(\begin{array}{cc}
0 & b \\
-b & 0
\end{array}\right)
$$$$
=\left(\begin{array}{cc}
b^{2} & a b \\
-b a & -b^{2}
\end{array}\right)+\left(\begin{array}{ll}
-b^{2} & a b \\
-b a & b^{2}
\end{array}\right)
$$$$
=\left(\begin{array}{cc}
0 & 2 b a \\
-2 b a & 0
\end{array}\right) \text {. Since char. } \mathrm{R}=2 \text {, then }
$$

$=\left(\begin{array}{ll}0 & 0 \\ 0 & 0\end{array}\right)$.Then $\mathrm{d}$ is skew- centralizing and

skew-commuting on $\mathrm{R}$, i.e. $\mathrm{d}(\mathrm{R})=\mathrm{O}$.

Also when we have $\mathrm{d}$ acts as homomorphism (resp. acts as an anti-homomorphism).

$$
\begin{aligned}
& \mathrm{d}(\mathrm{x}) \mathrm{d}(\mathrm{x})=\mathrm{d}\left(\left(\begin{array}{ll}
a & b \\
b & a
\end{array}\right)\right) \mathrm{d}\left(\left(\begin{array}{ll}
a & b \\
b & a
\end{array}\right)\right) \\
& =\mathrm{d}\left(\left(\begin{array}{ll}
a & b \\
b & a
\end{array}\right)\left(\begin{array}{ll}
a & b \\
b & a
\end{array}\right)\right) \\
& =\mathrm{d}\left(\left(\begin{array}{ll}
a^{2}+b^{2} & a b+b a \\
b a+b a & a^{2}+b^{2}
\end{array}\right)\right) \\
& =\left(\begin{array}{cc}
0 & 2 b a \\
-2 b a & 0
\end{array}\right) \cdot \text { Since char. } \mathrm{R}=2 \text {, we obtain } \\
& =\left(\begin{array}{cc}
0 & 0 \\
0 & 0
\end{array}\right) . \text { Thus d is skew-centralizing and }
\end{aligned}
$$

skew-commuting on $R$, i.e. $d(R)=o$.

\section{Acknowledgements}

The author would like to thank the referee for her/his useful comments.

\section{REFERENCES}

[1] S. Andima and H. Pajoohesh, Commutativity of prime rings with derivations, Acta Math. Hungarica, Vol. 128 (1-2) (2010), 1-14.

[2] G.A. Baker, A new derivation of Newton's identities and their application to the calculation of the eigenvalues of a matrix. J. Soc. Indust. Appl.Math. 7 (1959) 143-148.

[3] H. E. Bell and M. N. Daif, On derivations and commutativity in primerings. Acta Math. Hungar. Vol. 66 (1995), 337-343.

[4] I. N. Herstein, A note on derivations. Canad. Math. Bull, 21 (1978), 369-370.

[5] H. Pajoohesh, Positive derivations on lattice ordered rings of Matrices, Quaestiones Mathematicae, Vol. 30, (2007), 275-284.

[6] N.Divinsky, On commuting automorphisms of rings, Trans. Roy. Soc. Canada. Sect.III.(3)49(1955), 19-22.

[7] E.C.Posner, Derivations in prime rings. Proc.Amer.Math. Soc.8(1957).1093-1100.

[8] J. Luch. A note on commuting automorphisms of rings, Amer. Math. Monthly 77(1970), 61-62.

[9] M.N.Daif, Commutativity results for semiprime rings with derivations,Internat.J.Math.andMath.Sci.Vol.21,3(1998),471 -474 .

[10] M.N.Daif and H.E.Bell, Remarks on derivations on semiprime rings, Internat. J. Math. and Math.Sci.,15(1992),205-206 .

[11] V.DeFilippis, Automorphisms and derivations in prime rings, Rendiconti di Mathematica, Serie VII ,Vol.19, Roma (1999), 
393-404 .

[12] A.H.Majeed and Mehsin Jabel, Some results of prime and semiprime rings with derivations , Um-Salama Science J. , Vol. 2 (3) (2005), $508-516$.

[13] M. Bresar, On certain pairs of functions of semiprime rings, Proc. Amer. Math. Soc. 120 (1994),no. 3,709-713.

[14] M.Bresar, On skew-commuting mappings of rings,Bull.Austral.Math.Soc., Vol.47(1993),291-296.

[15] H.E.Bell and W.S.Martindale III, Centralizing mappings of semiprime rings, Canad Math. Bull.,30(1)(1987),92-101 .

[16] A.B.Thaheem and M.S.Samman, A note on $\alpha$-derivations on semiprime rings, Demonstration Math.,No.4,34(2011),783-788.

[17] Mehsin Jabel and Dalal Rasen, Skew-commuting and commuting derivations of semiprime rings, Journal of The
Basic Education-Al-Mustansiriyah

University,Vol.17,No.67,(2011),137-142.

[18] Mehsin Jabel, Generalized derivations of semiprime rings , Lambert Academic Publishing, Germany (2012).

[19] Mehsin Jabel, Commutativity results with derivations on semiprime rings. Journal of Mathematical and Computational Science, No. 4, 2(2012), 853-865.

[20] Mehsin Jabel, Derivations of semiprime rings with left cancellation property, Cayley Journal of Mathematics,Vol.1,(1)(2012),71-75.

[21] M.A.Chaudhryand A.B.Thaheem, A Note on A pair of derivations of semiprime rings, IJMMS 2004:39, 20972102,PII. S0161171204302139,http://ijmms.hindawi.com, Hindawi Publishing Corp. 